\title{
POTENTIAL BENEFIT OF CURCUMIN ADJUVANT THERAPY TO THE STANDARD HELICOBACTER PYLORI ERADICATION THERAPY IN PATIENTS WITH PEPTIC ULCER DISEASE
}

\author{
SHAYMAA HASAN ABBAS ${ }^{1}$, MANAL KHALID ABDULRIDHA ${ }^{1 *}$, AKRAM AJEEL NAJEB ${ }^{2}$ \\ ${ }^{1}$ Department of Clinical Pharmacy, College of Pharmacy, Al-Mustansiriya University, Iraq. ${ }^{2}$ Consultant Gastroenterologist, Baghdad \\ Teaching Hospital, Medical city, Iraq. Email: pharm.mrdha@uomustansiriyah.edu.iq
}

Received: 02 February 2017, Revised and Accepted: 27 February 2017

\section{ABSTRACT}

Objective: This study was designed to explore the benefit of curcumin as adjuvant therapy to the standard Helicobacter pylori eradication triple therapy in both duodenal and gastric ulcers patients.

Methods: The present study enrolled 40 patients newly diagnosed endoscopically with peptic ulcer disease to be allocated into group 1 treated with standard H. pylori eradication triple therapy, and group 2 patients treated with curcumin (500 mg) capsules three times daily for 14 days as an adjuvant to standard triple therapy. Stool antigen test, immunoglobulin M serology test, tumor necrosis factor-alpha (TNF- $\alpha$ ), interleukin 1 beta (IL-1 $\beta$ ), and total antioxidant capacity (T-AOC) are measured at the baseline and after 6 weeks of treatment.

Results: The result showed that the use of curcumin as adjuvant therapy produced highly significant improvement in healing efficacy which was significantly distinguished in duodenal ulcer patients compared to gastric ulcer groups 2 patients $(\mathrm{p}<0.05)$, along with a highly significant reduction in pro-inflammatory IL-1 $\beta$ level in group 2 patients $(p<0.01)$. After 6 weeks of treatment, there was a highly significant elevation in the level of TNF- $\alpha$ in groups 1 ( $\mathrm{p}<0.01)$, though group 2 patients presented with non-significant elevation in TNF- $\alpha$ level. Moreover, the T-AOC was improved with curcumin adjuvant therapy, though non-significant, compared to group 1 patients who showed a reduction in T-AOC.

Conclusion: This study revealed that addition of curcumin as adjuvant therapy produced improvement in ulcer healing efficacy, and controlled the inflammatory and oxidative stress process induced by H. pylori infection.

Keywords: Peptic ulcer disease, Curcumin, Helicobacter pylori infection, Inflammation, Oxidation markers.

(c) 2017 The Authors. Published by Innovare Academic Sciences Pvt Ltd. This is an open access article under the CC BY license (http://creativecommons. org/licenses/by/4. 0/) DOI: http://dx.doi.org/10.22159/ajpcr.2017.v10i5.17462

\section{INTRODUCTION}

Peptic ulcer disease (PUD) is the erosion in lining of stomach or duodenum [1]. Predominantly caused by Helicobacter pylori infection in about $50 \%$ of the world's population [2], which can colonize in the gastric antrum of all patients producing an extensive, noninvasive inflammatory reaction in the gastric mucosa [3]. It stimulates overexpression of pro-inflammatory cytokines (e.g., tumor necrosis factor $[\mathrm{TNF}-\alpha]$ and interleukin [IL-1 $\beta, \mathrm{IL}-6$, and IL-8]) in gastric epithelial cells, which activate neutrophil and lead to leukocyte infiltration [4]. There is an increasing difficulties in the conventional H. pylori eradication triple therapy mostly due to antimicrobial resistance [5], which were replaced with many other H. pylori eradication protocols [6]. Experimentally, a combination of standard anti-ulcer drugs and herbal medicines displayed a synergistic effect against gastric ulcer and could be used as alternative perspectives in treating certain gastric ulcers and preventing recurrence [7]. Curcumin is the main natural polyphenol present in the rhizome of Curcuma longa [8]. It is a lipophilic polyphenol which is nearly insoluble in water, but quite stable in acidic $\mathrm{pH}$ of the stomach [9]. It has poor bioavailability and selectivity [10]. Curcumin is widely used in herbal medicine because it possesses many pharmacological properties [11]. Moreover, as a monotherapy, it exhibits remarkable anti-inflammatory, antioxidant, antimicrobial, and anticarcinogenic effect [12]. Besides it display antiulcer activity by attenuating different ulcerative effectors including gastric acid hypersecretion, myeloperoxidase activity, apoptotic incidence, total peroxides, and IL-6, along with its inhibitory activity for pepsin [13]. Several properties help to recognize its anti- $H$. pylori effect, including pro-apoptotic effect, inhibition of angiogenesis, proliferation, and metastasis [14]. Accordingly, this study was designed to explore the benefit of curcumin as adjuvant therapy to the standard $H$. pylori eradication triple therapy in increasing the healing efficacy, changes in inflammatory markers, improving total antioxidant capacity (T-AOC) of both duodenal and gastric ulcers patients.

\section{MATERIAL AND METHODS}

\section{Study design}

The present study is a prospective randomized controlled interventional open-label study designed to track the potential effect of curcumin adjuvant therapy in PUD patients.

\section{Patients}

Forty patients newly diagnosed with PUD (26 females and 14 males) with age ranges between 17 and 70 years, attended the endoscopy unit were enrolled in the study after signing a written consent with ethical approval released by the institution scientific committee. The eligible patients were allocated into group 1 include (19) treated with standard H. pylori eradication triple therapy (clarithromycin [500 mg] tablets [Limassol, Cyprus] + amoxicillin [1 g] capsules [Bristol, UK] + esomeprazole [20 mg] tablets [Astrazeneca, Sweden]) all to be given twice daily for 14 days duration, which represent the control group, and group 2 include (21) patients treated with curcumin $(500 \mathrm{mg})$ capsules three times daily for 14 days as adjuvant with the standard H. pylori eradication triple therapy, which represents the interventional group.

\section{Methods}

Measurement of H. pylori

The H. pylori antigen rapid test device (feces) (ABON, China) and H. pylori immunoglobulin M antibody ELISA Kit (Cal biotech, USA) are used for $H$. pylori detection in group 1 and group 2 patients at the baseline and after 6 weeks treatment. 


\section{Measurement of serum TNF- $\alpha$}

It was determined using commercial enzyme-linked immunosorbent assay (ELISA) kit (Elabscince Biotechnology, China), measured in group 1 and group 2 patients at the baseline and after 6 weeks treatment.

\section{Measurement of serum IL-1 $\beta$}

It was determined using commercial ELISA kit (Elabscince Biotechnology, China), measured in group 1 and group 2 patients at the baseline and after 6 weeks treatment.

\section{Measurement of serum}

T-AOC: It was determined using commercial ELISA kit (QayeeBio, China), measured in group 1 and group 2 patients at the baseline and after 6 weeks treatment.

\section{Statistical analysis}

The statistical analysis system-Minitab 16.1 (2010) was used to see the effect of different factors on the study parameters. Least significant difference test was used to significantly compare between study parameters, where data expressed as (mean \pm standard deviation) with $(p>0.05)$ to be considered not significant, $\left({ }^{*} p<0.05\right)$ to be considered as significant, and $\left({ }^{* *} \mathrm{p}<0.01\right)$ to be considered as highly significant. Paired t-test was used to compare between pre- and post-treatment results and the two-sample t-test is used to compare pre- or post-treatment between group 1 and group 2 .

\section{RESULTS}

\section{Demographic data and disease characteristics of patients with} PUD

The study groups are allocated into group 1 (19 patients) which represents the comparative control, and group 2 (21 patients) which represents the intervention group (Table 1). The mean age of peptic ulcer patients in group 1 was $41.16 \pm 12.26$ years, and the mean age of patients in group 2 was $44.09 \pm 15.43$ years. The mean body mass index (BMI) of group 1 patients was $27.57 \pm 5.89 \mathrm{~kg} / \mathrm{m}^{2}$, and for group 2 patients was $26.66 \pm 4.28 \mathrm{~kg} / \mathrm{m}^{2}$. Group 1 include $(63.16 \%)$ female and (36.84\%) male genders, while group 2 include $(66.67 \%)$ female and (33.33\%) male. Peptic ulcer patients represented $(63.18 \%)$ as duodenal ulcer and $52.63 \%$ as gastric ulcer in group 1, and $61.90 \%$ as duodenal ulcer and $47.61 \%$ as gastric ulcer in group 2 . Positive family history was seen in $10.5 \%$ of patients in group 1 and $9.52 \%$ in group 2 . There was no statistically significant difference in the mean values of age, BMI, gender, type of peptic disease and family history between both study group patients ( $p>0.05)$. The duration of symptoms of less than 1 years was $78.95 \%$, and between 1 and 5 years was $21.05 \%$ in group 1 patients. While in group 2 patients the duration of symptoms of less than 1 year was $52.38 \%$, and between 1 and 5 years was $47.62 \%$. There was no patient presented with symptoms exceeding (5) years. The statistically significant difference was found in the duration of symptoms of $<1$ years $(\mathrm{p}<0.05)$ and highly significant difference in duration of symptoms of $(1-5)$ years $(\mathrm{p}<0.01)$ between both groups. The smoking habit was positive in $15.79 \%$ of group 1 patients and $14.29 \%$ of group 2 with no statistical difference between both groups $(\mathrm{p}>0.05)$.

Effect of $H$. pylori eradication triple therapy alone and in combination with curcumin on healing efficacy after 6 weeks of treatment

Group 1 peptic ulcer patients presented with (57.89\%) of healing efficacy after $H$. pylori eradication with standard triple therapy, while the mean percentage of healing efficacy of standard triple therapy in combination with curcumin in group 2 peptic ulcer patients was $(89.47 \%)$ after 6 weeks of treatment. Statistically high significant difference in healing efficacy was found among both study groups 1 and 2 patients $(\mathrm{p}<0.01)$ after 6 weeks up ceiling for group 2 patients on curcumin adjuvant therapy (Table 2). According to the location of ulcer, there was a statistically significant increase in the percentage of ulcer healing efficacy of $H$. pylori in groups 2 duodenal ulcer patients compared to groups 1 patients $(\mathrm{p}<0.05)$ after 6 weeks of treatment, with no significant difference in respect to gastric ulcer patients.

Effect of $H$. pylori eradication triple therapy alone and in combination with curcumin on inflammatory markers in peptic ulcer patients after 6 weeks of treatment

In the present study, there was no statistically significant difference at the baseline level of TNF- $\alpha$ between both study groups 1 and 2 ( $p>0.05$ ). After 6 weeks of treatment, there was highly significant increase in the level of TNF- $\alpha$ in groups 1 ( $\mathrm{p}<0.01$ ), but in group 2 patients, the increase in TNF- $\alpha$ level presented was non-significant after 6 weeks of treatment compared to the pretreatment level ( $p>0.05$ ) (Table 3). Moreover, there was no statistically significant difference at the baseline level of IL-1 $\beta$ between both study groups 1 and 2 ( $p>0.05$ ). After 6 weeks of treatment, results of group 2 patients showed highly significant decrease in the level of IL-1 $\beta$ compared to pretreatment level $(\mathrm{p}<0.01)$, while group 1 patients presented with no significant decrease in IL-1 $\beta$ level ( $p>0.05)$.

Effect of $H$. pylori eradication triple therapy alone and in combination with curcumin on T-AOC in peptic ulcer patients after 6 weeks of treatment

There was no significant difference at the baseline level of mean T-AOC between both study groups 1 and 2 ( $p>0.05$ ). However, after 6 weeks of treatment there was an increase in the level of mean T-AOC in study groups 2 patients, though non-significant, patients in study group 1 showed a reduction in the level of mean T-AOC compared to pretreatment level $(\mathrm{p}>0.05)$ (Table 4).

\section{DISCUSSION}

The H. pylori infection is a worldwide problem in patients with PUD with a high rate of morbidity and mortality $[15,16]$. Several studies were conducted to evaluate the most effective therapeutic regimen for improving the eradication rate of $H$. pylori infection and obtaining higher healing efficacy [17-21]. This study is another attempt in this respect, though at a smaller scale, which might be (at least to best knowledge) the first attempt to evaluate the efficacy of curcumin as an adjuvant to the standard triple $H$. pylori eradication therapy.

Table 1: Demographic data and disease characteristics of patients with peptic ulcer disease

\begin{tabular}{|c|c|c|c|}
\hline \multirow[t]{2}{*}{ Variable } & \multicolumn{3}{|l|}{ Study groups } \\
\hline & Group $1(n=19)$ & Group $2(n=21)$ & p value \\
\hline Age (years) & $41.16 \pm 12.26$ & $44.09 \pm 15.43$ & $0.751^{\mathrm{NS}}$ \\
\hline Range (years) & $20-63$ & $17-70$ & \\
\hline $\begin{array}{l}\text { BMI kg/m² } \\
\text { Gender }\end{array}$ & $27.57 \pm 5.89$ & $26.66 \pm 4.28$ & $0.902^{\mathrm{NS}}$ \\
\hline Female & $12(63.16)$ & $14(66.67)$ & $0.751^{\mathrm{NS}}$ \\
\hline Male & $7(36.84)$ & $7(33.33)$ & $0.679^{\mathrm{NS}}$ \\
\hline Total & $19(100)$ & $21(100)$ & \\
\hline \multicolumn{4}{|l|}{ Type of PUD } \\
\hline Duodenal ulcer & $12(63.18)$ & $13(61.90)$ & $0.909^{\mathrm{NS}}$ \\
\hline Gastric ulcer & $10(52.63)$ & $10(47.61)$ & $0.616^{\mathrm{NS}}$ \\
\hline \multicolumn{4}{|l|}{ Family history } \\
\hline Positive & $2(10.5)$ & $2(9.52)$ & $0.827^{\mathrm{NS}}$ \\
\hline Negative & $17(89.47)$ & $19(90.48)$ & $0.940^{\mathrm{NS}}$ \\
\hline \multicolumn{4}{|l|}{$\begin{array}{l}\text { Duration of } \\
\text { symptoms (years) }\end{array}$} \\
\hline$<1$ & $15(78.95)$ & $11(52.38)$ & $0.02^{*}$ \\
\hline $1-5$ & $4(21.05)$ & $10(47.62)$ & $0.001^{* *}$ \\
\hline$>5$ & - & - & \\
\hline \multicolumn{4}{|l|}{ Smoking habit } \\
\hline Positive & 3 (15.79) & 3 (14.29) & $0.784^{\mathrm{NS}}$ \\
\hline Negative & $16(84.21)$ & $18(85.7)$ & $0.909^{\mathrm{NS}}$ \\
\hline
\end{tabular}

Data presented as mean $\pm \mathrm{SD}$; $(\mathrm{n})$ is number of patients and (\%) is a percentage. Chi-square test for numerical values to compare between group 1 and group 2 where; NS: Not significant $(\mathrm{p}>0.05) ;{ }^{*}(\mathrm{p}<0.05)$ is considered significant; $* *(\mathrm{p}<0.01)$ is considered highly significant. BMI: Body mass index, PUD: Peptic ulcer disease, SD: Standard deviation 
Table 2: Effect of $H$. pylori eradication triple therapy alone and in combination with curcumin on healing efficacy after 6 weeks of treatment

\begin{tabular}{|c|c|c|c|c|c|}
\hline \multirow[t]{2}{*}{ Study groups } & \multirow[t]{2}{*}{ Patient (n) } & \multirow{2}{*}{$\begin{array}{l}\text { Ulcer healing efficacy } \\
\text { n (\%) }\end{array}$} & \multicolumn{3}{|c|}{ Ulcer healing efficacy } \\
\hline & & & DU n (\%) & GU n (\%) & p value \\
\hline Group 1 & 19 & 11 of $19(57.89)$ & 6 of $12(50.00)$ & 5 of $10(50.00)$ & $1.00^{\mathrm{NS}}$ \\
\hline Group 2 & 21 & 17 of 21 (89.47) & 10 of $13(76.92)$ & 7 of $10(70.00)$ & $0.859^{\mathrm{NS}}$ \\
\hline $\mathrm{p}$ value & & $0.009 * *$ & $0.017^{*}$ & $0.564^{\mathrm{NS}}$ & \\
\hline
\end{tabular}

Data presented as; (n) is number of patients and (\%) is a percentage. Chi-square test for numerical values to compare between group 1 and group 2 where;

NS: Not significant $(\mathrm{p}>0.05) ;{ }^{*}(\mathrm{p}<0.05)$ is considered significant; ${ }^{* *}(\mathrm{p}<0.01)$ is considered highly significant. H. pylori: Helicobacter pylori

Table 3: Effect of H. pylori eradication triple therapy alone and in combination with curcumin on inflammatory markers in peptic ulcer patients after 6 weeks of treatment

\begin{tabular}{llll}
\hline Variable & \multicolumn{2}{l}{ Study groups } & \\
\cline { 2 - 4 } & Group 1 (n=19) & Group 2 (n=21) & p value \\
\hline TNF- $\alpha(\mathrm{pg} / \mathrm{ml})$ & & & \\
Pre-treatment & $12.78 \pm 11.67$ & $22.02 \pm 18.87$ & $0.069^{\mathrm{NS}}$ \\
Post-treatment & $27.43 \pm 19.60$ & $29.19 \pm 20.29$ & $0.782^{\mathrm{NS}}$ \\
p value & $0.004^{* *}$ & $0.149^{\mathrm{NS}}$ & \\
IL-1 $\beta$ (pg/ml) & & & \\
Pre-treatment & $13.186 \pm 11.15$ & $24.69 \pm 23.85$ & $0.057^{\mathrm{NS}}$ \\
Post-treatment & $9.12 \pm 8.89$ & $7.713 \pm 5.7$ & $0.561^{\mathrm{NS}}$ \\
p value & $0.099^{\mathrm{NS}}$ & $0.002^{* *}$ & \\
\hline
\end{tabular}

Data presented as mean \pm SD. Paired $t$-test to compare pre and post treatmen variables and two sample t-test to compare pre- or post-treatment variables where; NS: Not significant $(\mathrm{p}>0.05),{ }^{* *}(\mathrm{p}<0.01)$ is considered highly significant. SD: Standard deviation, TNF- $\alpha$ : Tumor necrosis factor-alpha, IL-1 $\beta$ : Interleukin 1 beta

Table 4: Effect of $\boldsymbol{H}$. pylori eradication triple therapy alone and in combination with curcumin on T-AOC in peptic ulcer patients after 6 weeks of treatment

\begin{tabular}{|c|c|c|c|}
\hline Variable & Study groups & & \\
\hline T-AOC (ng/ml) & Group $1(n=19)$ & Group $2(n=21)$ & $p$ value \\
\hline Pre treatment & $50.7 \pm 45$ & $37.06 \pm 12.66$ & $0.216^{\mathrm{NS}}$ \\
\hline $\begin{array}{l}\text { Post treatment } \\
p \text { value }\end{array}$ & $\begin{array}{l}47.63 \pm 25.27 \\
0.73^{\mathrm{NS}}\end{array}$ & $\begin{array}{l}40.31 \pm 13.24 \\
0.108^{\mathrm{NS}}\end{array}$ & $0.268^{\mathrm{NS}}$ \\
\hline
\end{tabular}

Data presented as mean \pm SD. Paired t-test to camper pre- and post-treatment variables and two sample t-test to compare pre- or post-treatment variables where; NS: Not significant ( $\mathrm{p}>0.05)$. SD: Standard deviation,

H. pylori: Helicobacter pylori, T-AOC: Total antioxidant capacity

The activity of curcumin alone in PUD was experimentally in vitro investigated previously as possessing antioxidant and anti-inflammatory properties, and to attenuating gastric hypersecretion (as a major pathology caused by $H$. pylori microorganism in gastric and duodenal ulcer) [13]. In addition, apoptotic and myeloperoxidase activity, along with its inhibitory effect for pepsin was found [13]. Moreover, several other in vivo and in vitro studies explored the inhibitory effect of curcumin against $H$. pylori growth, consequently eradicate $H$. pylori infection [22-24]. In clinical trials, curcumin supplement alone is still under investigation in which it is expected to play a potential role in suppressing $H$. pylori growth, and may promote healing of peptic ulcers $[25,26]$.

In the present study, and in many others, patients with PUD caused by $H$. pylori infection were mostly in a middle age of $<50$ years [27-30]. Female patients had the higher rate of infection with $H$. pylori microorganism, similar finding was found among Iraqi population in other studies [31,32], inversely, male gender was predominant to females in others $[33,34]$. Higher percentage of peptic ulcer patients diagnosed endoscopically as duodenal ulcer compared to these with gastric ulcer in the present study. This finding was in agreement with previous cohort study on PUD patients [35]. Comparable results showed that patients with duodenal ulcers had a higher rate of $H$. pylori infection [36,37].

Positive family history and smoking habits were correlated positively with the incidence of PUD in a previous study [38]. The H. pylori infections tend to distributed within families by close person-toperson contact [39], hence, H. pylori infection has a high risk to develop gastroduodenal diseases in individuals with positive family history [40]. Other data reported by Shokrzadeh et al. showed that positive family history of PUD was seen in about $24 \%$ of $H$. pylori positive patients [40]. Furthermore, the present study reported statistically significant difference in duration of symptoms $<1$ years and high significant difference in duration of symptoms 1-5 years between both study groups 1 and 2 , while there were no patients presented with symptoms exceeding 5 years.

Recalling that curcumin possess inhibiting effect on gastric acid secretion, inhibiting the activity of pepsin, and reducing juice acidity [13]. Furthermore, it poses inhibiting effect against NFKB activation and macromolecular leakage induced by $H$. pylori infection; all would explain ulcer healing property of curcumin [26].

In the present study, the healing efficacy of peptic ulcer was increased from (57.89\%) with slandered triple therapy alone up to (89.47\%) after addition of curcumin adjuvant therapy. The therapeutic potential of curcumin as a monotherapy against $H$. pylori infection was elegantly studied and reviewed previously by many researchers [5,22,41,42], meanwhile Di Mario et al. stated that administration of 7 days curcumin $30 \mathrm{mg}$ b.i.d, bovine lactoferrin $100 \mathrm{mg}$ b.i.d, N-acetylcysteine $600 \mathrm{mg}$ b.i.d, and pantoprazole $20 \mathrm{mg}$ b.i.d produce only (12\%) cure of dyspeptic patients infected with $H$. pylori, nevertheless, a significant reduction in severity of overall symptoms after 2 months was noticed [43].

With reference to the global trend of $H$. pylori eradication therapy which has now shifted towards proton pump inhibitor (PPI)-based triple therapy (a PPI and different antimicrobials) [6], which was studied extensively on Iraqi group of patients as well $[21,44]$ can assure rapid symptom relief, reduce ulcer recurrence, and improve ulcer healing. However, many bacterial and host factors are contribute to the failure of H. pylori eradication, especially factors affecting PPI bioavailability and metabolism $[45,46]$, besides the low patient compliance, especially in elderly patients $[47,48]$. In the last decades, the increasing incidence of clarithromycin-resistant strains of $H$. pylori became the most important cause for treatment failure [46,49]. Taken together all these facts, this study might be a new trend towards improving $H$. pylori eradication rate with the addition of curcumin to the (PPI)-based triple therapy, which alone revealed a (42.1\%) eradication failure rate.

The current study explored that the addition of curcumin to the standard $H$. pylori triple therapy produce a significant increase in ulcer healing efficacy in both patient groups with up ceiling effect in duodenal ulcers $(76.92 \%$ vs70\%) when compared with standard H. pylori eradication triple therapy. These results were in agreement with that of Purcksunand et al. who found that healing efficacy after curcumin as a mono-treatment for 3 months was (73\%) in patients with duodenal ulcer and $(27 \%)$ in patients with gastric ulcer in phase II clinical 
trial [26]. The predominant colonization of $H$. pylori in the duodenal region [50], along with the inhibitory effect of curcumin against $H$. pylori growth and attenuating gastric hypersecretion (as a major pathology caused by $H$. pylori microorganism in gastric and duodenal ulcer) as mentioned earlier, this would make acceptable explanation for the incremental healing efficacy in duodenal ulcers.

The key physiological event in $H$. pylori infection is the induction of inflammatory response in the gastric mucosa. This microorganism stimulates transcription and synthesis of many inflammatory cytokines especially IL-1 $\beta$ and TNF- $\alpha$ [51]. The effect of curcumin on the inflammatory markers induced by $H$. pylori infection in peptic ulcer patients is still under investigation, several studies were conducted to explore the anti-inflammatory effect of curcumin as a monotherapy [52-54]

In the present study, the addition of curcumin to the standard triple H. pylori eradication therapy produce some suppressive effect against the up ceiling rise in the TNF- $\alpha$ level which was noticed significantly in patients on standard H. pylori triple therapy alone, giving some promising protective effect to the gastric and duodenal mucosa against H. pylori virulence.

Moreover, in the present study, curcumin adjuvant therapy produced highly significant reduction $(\mathrm{p}<0.01)$ in mean IL-1 $\beta$ level (another pro-inflammatory mediator) in comparison with patients treated with standard $H$. pylori triple therapy alone after 6 weeks treatment. No matched interventional study was available to precisely interpret these results, though, it can be said that curcumin might produce synergistic anti-inflammatory effect which cannot be obtained when using standard H. pylori triple therapy alone.

The inhibitory effect of curcumin monotherapy on IL- $1 \beta$ and TNF- $\alpha$ production in ulcerated gastric mucosa caused by $H$. pylori infection was documented experimentally $[23,24,26,55]$ and was detected in the human study [56], with some controversy [42]. Kundu et al. suggested that curcumin act by two ways against $H$. pylori infection; first as antibacterial via eradicating $H$. pylori infection, and second; potentially targeting key molecules involved in the $H$. pylori -induced gastric diseases [23]. In addition, Di Mario et al. found that treatment with curcumin significantly reduces the serologic signs of gastric inflammation associated with $H$. pylori infection despite the persistence of the bacterium [43]. Curcumin can also prevent indomethacin-induced gastropathy by improvement the gastric microcirculation through attenuating the level of intercellular adhesion molecule (ICAM)-1and TNF $\alpha$ levels compared to treatment with indomethacin alone [57]. IL-1 genetic polymorphisms influenced H. pylori-related gastric mucosal IL- $1 \beta$ levels which may lead to gastric inflammation and atrophy; factors thought to be important in gastric carcinogenesis [58], it can be speculated that curcumin potentially plays a role in this aspect.

Oxidative stress may represent an important mechanism leading to epithelial injury in H. pylori infection [59], characterized by an increase in the reactive oxygen species levels in the infected patient's mucosa [60]. There was statistically incremental elevation, though non-significant, in the level of T-AOC in the present study after 6 weeks of treatment with curcumin adjuvant therapy, and a decrease in T-AOC with standard $H$. pylori triple therapy alone. In vitro study, Tuba et al. found that ethanolic extract of $C$. longa leaves had the ability to attenuate the free radical mediated lipid peroxidation and scavenged free radical [61]. The anti-oxidant and free radical scavenging effects of curcumin counteracted with reactive oxygen and nitrogen species thereby protected cells from oxidative damage [62]. Experimentally, Abdul-Aziz found a significant increase in TAO-C level in serum and gastric juice after treatment with curcumin alone for a stomach ulcer in Shay rat model [63], and the level of total peroxides was significantly reduced in serum and gastric juice of curcumin treated rats [63]

\section{CONCLUSION}

This study revealed that addition of curcumin as an adjuvant to standard triple $H$. pylori eradication therapy produced improvement in ulcer healing efficacy in peptic ulcer patients, and controlled the inflammatory and oxidative stress process induced by $H$. pylori infection, allowing to speculate the promising therapeutic effect of curcumin as an adjuvant therapy.

\section{ACKNOWLEDGMENT}

The authors would like to thank Al-Mustansiriyah University (www.uomustansiriyah.edu.iq), Baghdad - Iraq for its support in the present work and special thanks to Baghdad Teaching Hospital, Medical city for their help in providing the practical platform of this study.

\section{REFERENCES}

1. Sivakumar G, Ragini KP, Kumar NS, Sekhar S, Rao C, Ayyanna C. Evaluation of anti-ulcer activity of hydroalcoholic extract of the Terminalia arjuna bark. Int J Pharm Pharm Sci 2012;4(3):203-5.

2. Kusters JG, van Vliet AH, Kuipers EJ. Pathogenesis of Helicobacter pylori infection. Clin Microbiol Rev 2006;19(3):449-90.

3. Verbeke H, Geboes K, Van Damme J, Struyf S. The role of CXC chemokines in the transition of chronic inflammation to esophageal and gastric cancer. Biochim Biophys Acta 2012;1825(1):117-29.

4. Zaidi SF, Ahmed $\mathrm{K}$, Yamamoto $\mathrm{T}$, Kondo $\mathrm{T}$, Usmanghani $\mathrm{K}$, Kadowaki M, et al. Effect of resveratrol on Helicobacter pyloriinduced interleukin- 8 secretion, reactive oxygen species generation and morphological changes in human gastric epithelial cells. Biol Pharm Bull 2009;32:1931-5.

5. De R, Kundu P, Swarnakar S, Ramamurthy T, Chowdhury A, Nair GB, et al. Antimicrobial activity of curcumin against Helicobacter pylori isolates from India and during infections in mice. Antimicrob Agents Chemother 2009;53(4):1592-7.

6. Fashner J, Gitu AC. Diagnosis and treatment of peptic ulcer disease and H. pylori infection. Am Fam Physician 2015;91(4):236-42.

7. Xie JH, Chen YL, Wu QH, Wu J, Su JY, Cao HY, et al. Gastroprotective and anti-Helicobacter pylori potential of herbal formula HZJW: Safety and efficacy assessment. BMC Complement Altern Med 2013;13:119.

8. Nimmi OS, George P. Evaluation of the antioxidant potential of a newly developed polyherbal formulation for antiobesity. Int J Pharm Pharm Sci 2012;4(3):205-10

9. Jurenka JS. Anti-inflammatory properties of curcumin, a major constituent of Curcuma longa: A review of preclinical and clinical research. Altern Med Rev 2009;14(2):141-53

10. Anand P, Kunnumakkara AB, Newman RA, Aggarwal BB. Bioavailability of curcumin: Problems and promises. Mol Pharm 2007;4(6):807-18

11. Balachandran P, Govindarajan R. Cancer - An ayurvedic perspective. Pharmacol Res 2005;51(1):19-30.

12. Kewitz S, Volkmer I, Staege MS. Curcuma contra cancer? Curcumin and hodgkin's lymphoma. Cancer Growth Metastasis 2013;6:35-52.

13. Mei X, Xu D, Wang S, Xu S. Pharmacological researches of curcumin solid dispersions on experimental gastric ulcer. Zhongguo Zhong Yao Za Zhi 2009;34(22):2920-3.

14. Anto RJ, Mukhopadhyay A, Denning K, Aggarwal BB. Curcumin (Diferuloylmethane) induces apoptosis through activation of caspase-8, BID cleavage and cytochrome c release: Its suppression by ectopic expression of Bcl-2 and Bcl-xl. Carcinogenesis 2002;23(1):143-50.

15. Fuccio L, Eusebi LH, Bazzoli F. Gastric cancer, Helicobacter pylori infection and other risk factors. World J Gastrointest Oncol 2010;2(9):342-7

16. Alakkari A, Zullo A, O'Connor HJ. Helicobacter pylori and nonmalignant diseases. Helicobacter 2011;16 Suppl 1:33-7.

17. Fuccio L, Minardi ME, Zagari RM, Grilli D, Magrini N, Bazzoli F. Meta-analysis: Duration of first-line proton-pump inhibitor based triple therapy for Helicobacter pylori eradication. Ann Intern Med 2007;147(8):553-62.

18. Vaira D, Zullo A, Vakil N, Gatta L, Ricci C, Perna F, et al. Sequential therapy versus standard triple-drug therapy for Helicobacter pylori eradication: A randomized trial. Ann Intern Med 2007;146(8):556-63.

19. Greenberg ER, Anderson GL, Morgan DR, Torres J, Chey WD, Bravo LE, et al. 14-Day triple, 5-day concomitant, and 10-day sequential therapies for Helicobacter pylori infection in seven Latin American sites: A randomised trial. Lancet 2011;378(9790):507-14. 
20. Malfertheiner P, Bazzoli F, Delchier JC, Celiñski K, Giguère M, Rivière $\mathrm{M}$, et al. Helicobacter pylori eradication with a capsule containing bismuth subcitrate potassium, metronidazole, and tetracycline given with omeprazole versus clarithromycin-based triple therapy: A randomised, open-label, non-inferiority, phase 3 trial. Lancet 2011;377(9769):905-13.

21. Mohammed Ali ZA, Al-Mulla Hummadi YM, Najeeb AA. Triple and quadruple eradication therapy for $H$. pylori in Iraqi patients with peptic ulcer disease a comparative study. Br J Med Med Res 2015;7(3):231-40.

22. Han C, Wang L, Yu K, Chen L, Hu L, Chen K, et al. Biochemical characterization and inhibitor discovery of shikimate dehydrogenase from Helicobacter pylori. FEBS J 2006;273(20):4682-92.

23. Kundu P, De R, Pal I, Mukhopadhyay AK, Saha DR, Swarnakar S. Curcumin alleviates matrix metalloproteinase-3 and -9 activities during eradication of Helicobacter pylori infection in cultured cells and mice. PLoS One 2011;6:e16306.

24. Santos AM, Lopes T, Oleastro M, Gato IV, Floch P, Benejat L, et al. Curcumin inhibits gastric inflammation induced by Helicobacter pylori infection in a mouse model. Nutrients 2015;7(1):306-20.

25. Swarnakar S, Ganguly K, Kundu P, Banerjee A, Maity P, Sharma AV. Curcumin regulates expression and activity of matrix metalloproteinases 9 and 2 during prevention and healing of indomethacin-induced gastric ulcer. J Biol Chem 2005;280:9409-15.

26. Prucksunand C, Indrasukhsri B, Leethochawalit M, Hungspreugs K. Phase II clinical trial on effect of the long turmeric (Curcuma longa Linn) on healing of peptic ulcer. Southeast Asian J Trop Med Public Health 2001;32(1):208-15.

27. Hussein NR, Robinson K, Atherton JC. A study of age-specific Helicobacter pylori seropositivity rates in Iraq. Helicobacter 2008;13(4):306-7

28. Batista CA, Silva FM, Barbuti RC, Eisig JN, Mattar R, Navarro-Rodriguez T. Neither genotype nor the gastric colonization site of Helicobacter pylori are predictive factors for the development of erosive esophagitis in patients with peptic ulcer disease, 1 year after eradication. Arq Gastroenterol 2009;46(3):204-8.

29. Abdulridha MK. The relationship between ABO blood group distribution and the incidence of upper gastric and duodenal ulcer in Iraqi patients. Iraqi J Pharm Sci 2013;22(1):97-103.

30. Eusebi LH, Zagari RM, Bazzoli F. Epidemiology of Helicobacter pylori infection. Helicobacter 2014;19 Suppl 1:1-5.

31. Jaff MS. Relation between ABO blood groups and Helicobacter pylori infection in symptomatic patients. Clin Exp Gastroenterol 2011;4:221-6.

32. Al-Mossawei MT, Rzooqi WH, Abdulrazzaq S. Detection of Helicobacter pylori IgG and IgM antibodies in Iraqi dyspeptic patients. J Biotechnol Res Cent 2016;10(1):5-9.

33. Yakoob J, Abid S, Jafri W, Abbas Z, Mumtaz K, Hamid S, et al. Low rate of recurrence of Helicobacter pylori infection in spite of high clarithromycin resistance in Pakistan. BMC Gastroenterol 2013;13:33.

34. Yasir S, Moin F, Akhtar SM. Frequency of Helicobacter pylori infection on histopathology in patients with dyspepsia. Am J Clin Med Res 2014;2(3):53-6.

35. Rosenstock S, Jørgensen T, Bonnevie O, Andersen L. Risk factors for peptic ulcer disease: A population based prospective cohort study comprising 2416 Danish adults. Gut 2003;52(2):186-93

36. Ciociola AA, McSorley DJ, Turner K, Sykes D, Palmer JB. Helicobacter pylori infection rates in duodenal ulcer patients in the United States may be lower than previously estimated. Am J Gastroenterol 1999;94(7):1834-40.

37. Lee SW, Chang CS, Lee TY, Yeh HZ, Tung CF, Peng YC. Risk factors and therapeutic response in Chinese patients with peptic ulcer disease. World J Gastroenterol 2010;16(16):2017-22.

38. Rajashekhar V, Bhasin DK, Ray P, Vaiphei K, Sharma BC, Singh K. Helicobacter pylori infection in chronic smokers with non ulcer dyspepsia. Trop Gastroenterol 2000;21(2):71-2.

39. Linz B, Balloux F, Moodley Y, Manica A, Liu H, Roumagnac P, et al. An African origin for the intimate association between humans and Helicobacter pylori. Nature 2007;445(7130):915-8.

40. Shokrzadeh L, Baghaei K, Yamaoka Y, Shiota S, Mirsattari D, Porhoseingholi A, et al. Prevalence of Helicobacter pylori infection in dyspeptic patients in Iran. Gastroenterol Insights 2012;4(1):24-7.

41. Mahady GB, Pendland SL, Yun G, Lu ZZ. Turmeric (Curcuma longa) and curcumin inhibit the growth of Helicobacter pylori, a group 1 carcinogen. Anticancer Res 2002;22(6C):4179-81.

42. Koosirirat C, Linpisarn S, Changsom D, Chawansuntati K, Wipasa J. Investigation of the anti-inflammatory effect of Curcuma longa in Helicobacter pylori-infected patients. Int Immunopharmacol
2010;10(7):815-8

43. Di Mario F, Cavallaro LG, Nouvenne A, Stefani N, Cavestro GM, Iori $\mathrm{V}$, et al. A curcumin-based 1-week triple therapy for eradication of infection: Something to learn from failure? Helicobacter 2007; 12(3):238-43

44. Mohammed Ali ZA, Abdulridha MK, Najeb AA. Response to first -line quadruple and second- line quadruple $H$. pylori eradication therapy in Iraqi patients with peptic ulcer disease. World J Pharm Res 2015;4(10):2068-86.

45. Zullo A, De Francesco V, Hassan C. Predicting Helicobacter pylori eradication: How to teach an old dog new tricks! J Clin Gastroenterol 2012:46(4):259-61.

46. De Francesco V, Ierardi E, Hassan C, Zullo A. Helicobacter pylori therapy: Present and future. World J Gastrointest Pharmacol Ther 2012;3(4):68-73

47. Pilotto A, Salles N. Helicobacter pylori infection in geriatrics. Helicobacter 2002;7 Suppl 1:56-62.

48. Maev IV, Andreev DN, Kucheryavyi YA, Dicheva DT. Host factors influencing the eradication rate of Helicobacter pylori. World Appl Sci 2014:30:134-40.

49. Lee JY, Kim N, Kim MS, Choi YJ, Lee JW, Yoon H, et al. Factors affecting first-line triple therapy of Helicobacter pylori including CYP2C19 genotype and antibiotic resistance. Dig Dis Sci 2014;59(6):1235-43.

50. Lai YC, Wang TH, Huang SH, Yang SS, Wu CH, Chen TK, et al. Density of Helicobacter pylori may affect the efficacy of eradication therapy and ulcer healing in patients with active duodenal ulcers. World J Gastroenterol 2003;9(7):1537-40.

51. Sintara K, Thong-Ngam D, Patumraj S, Klaikeaw N, Chatsuwan T. Curcumin suppresses gastric NF-kappaB activation and macromolecular leakage in Helicobacter pylori-infected rats. World J Gastroenterol 2010;16(32):4039-46.

52. Singh S, Aggarwal BB. Activation of transcription factor NF-kappa B is suppressed by curcumin (Diferuloylmethane) [corrected]. J Biol Chem 1995;270(42):24995-5000

53. Kumar A, Dhawan S, Hardegen NJ, Aggarwal BB. Curcumin (Diferuloylmethane) inhibition of tumor necrosis factor (TNF)-mediated adhesion of monocytes to endothelial cells by suppression of cell surface expression of adhesion molecules and of nuclear factor-kappaB activation. Biochem Pharmacol 1998;55(6):775-83.

54. Jobin C, Bradham CA, Russo MP, Juma B, Narula AS, Brenner DA, et al. Curcumin blocks cytokine-mediated NF-kappa B activation and proinflammatory gene expression by inhibiting inhibitory factor I-kappa B kinase activity. J Immunol 1999;163(6):3474-83.

55. Mahattanadul S, Nakamura T, Panichayupakaranant $P$, Phdoongsombut N, Tungsinmunkong K, Bouking P. Comparative antiulcer effect of bisdemethoxycurcumin and curcumin in a gastric ulcer model system. Phytomedicine 2009;16(4):342-51

56. Ludwig AF, Neumann M, Brachert WS, Naumann M. Curcumin blocks NF-kappaB and the motogenic response in Helicobacter pylori-infected epithelial cells. Biochem Biophys Res Commun 2004;316(4):1065-72.

57. Hwang IR, Kodama T, Kikuchi S, Sakai K, Peterson LE, Graham DY, et al. Effect of interleukin 1 polymorphisms on gastric mucosal interleukin lbeta production in Helicobacter pylori infection. Gastroenterology 2002;123(6):1793-803

58. Thong-Ngam D, Choochuai S, Patumraj S, Chayanupatkul M, Klaikeaw N. Curcumin prevents indomethacin-induced gastropathy in rats. World J Gastroenterol 2012;18(13):1479-84.

59. Smoot DT, Elliott TB, Verspaget HW, Jones D, Allen CR, Vernon KG, et al. Influence of Helicobacter pylori on reactive oxygen-induced gastric epithelial cell injury. Carcinogenesis 2000;21(11):2091-5.

60. Drake IM, Mapstone NP, Schorah CJ, White KL, Chalmers DM, Dixon MF, et al. Reactive oxygen species activity and lipid peroxidation in Helicobacter pylori associated gastritis: Relation to gastric mucosal ascorbic acid concentrations and effect of $H$. pylori eradication. Gut 1998;42(6):768-71.

61. Ak T, Gülçin I. Antioxidant and radical scavenging properties of curcumin. Chem Biol Interact 2008;174(1):27-37.

62. Sarkar A, De R, Mukhopadhyay AK. Curcumin as a potential therapeutic candidate for Helicobacter pylori associated diseases. World J Gastroenterol 2016;22(9):2736-48.

63. Abdul-Aziz KK. Comparative evaluation of the anti-ulcer activity of curcumin and omeprazole during the acute phase of gastric ulcer-efficacy of curcumin in gastric ulcer prevention against omeprazole. Food Nutr Sci 2011;2:628-40 